\title{
0 uso da ISO 50001/14001 de gestão de energia na construção da imagem socioambiental das empresas
}

DOI: https://doi.org/10.35168/2176-896X.UTP.Tuiuti.2021.Vol7.N63.pp52-73

D.Sc. Rodrigo Dias

Universidade Federal do Paraná e Universidade Tuiuti do Paraná (UFPR e UTP). rodrigodias@coc.ufrj.br

Eng. Geovane Amâncio Alves Robert Bosch Ltda E ufpr; Programa de Pós graduação em Engenharia de Manufatura. geovane.alves@ufpr.br

Patricia Bellotti Carvalho Universidade Tuiuti do Paraná (UTP). patricia.bellotti@utp.br 


\section{0 uso da ISO 50001/14001 de gestão de energia na construção da imagem socioambiental das empresas}

\section{Resumo}

O Brasil é a $12^{a}$ economia do mundo atualmente, porém, é a $7^{a}$ no consumo total de energia, representando $2,3 \%$, tendo o setor industrial o mais representativo nessa fatia do consumo, representando 32,1\%. O processo de manufatura é o setor que mais contribui com esse enorme consumo. Com isso a eficiência energética e o processo de gestão de energia, vem ao encontro dessa busca por sustentabilidade. Tanto o consumo, quanto a gestão dos recursos, fazem parte desta estratégia, no desenvolvimento de novos mecanismos de produção, quanto uma maior eficiência e melhor gestão dos recursos naturais. Esse tema vem sendo estudado há algumas décadas e vem ganhando força nos últimos anos, por ser de interesse global, de modo a reduzir o consumo de energia e aumentar a oferta de novas formas de geração, de modo a reduzir os impactos ambientais. Para realização deste artigo, foi realizado uma ampla revisão bibliográfica de modo a focar em pesquisas recentes com análise qualitativa, fazendo assim, uma sintese desse conjunto de documentos de diversos autores que contribuiram fortemente, tanto na área acadêmica quanto industrial sobre eficiência energética e novos processos de geração, levando em conta os principais conceitos encontrados nas ISO's 5001 e 14001.

Palavras-chave: Eficiência energética. Sustentabilidade. Consumo de energia. 


\section{The use of ISO 50001/14001 of energy management in the construction of the socio-environmental image of companies}

\section{Abstract}

Brazil is currently the 12 th economy in the world, however, it is the 7 th in energy consumption, representing $2.3 \%$ of total, with no industrial sector being the most representative in this share of consumption, representing $32.1 \%$. The manufacturing process is the sector that contributes the most to this enormous consumption. Thus, energy efficiency and the energy management process meet this quest for sustainability. Both consumption and resource management are part of this strategy, in the development of new production mechanisms, in terms of greater efficiency and better management of natural resources. This topic has been studied for some decades and has been gaining strength over the years, as it is of global interest, to reduce energy consumption and increase the offer of new forms of generation, that one may reduce environmental impacts. With the aim of carry out this article, a broad review of this article will be carried out, a broad bibliographic review will be carried out to achieve to focus on recent research with qualitative analysis, thus making a synthesis of this set of documents from several authors who have contributed strongly, both in the academic area. Regarding industrial efficiency and new generation processes, considering the main concepts found in ISO's 5001 and 14001.

Keywords: Energy Efficiency. Sustainability. Energy Consumption. 


\section{0 uso da ISO 50001/14001 de gestão de energia na construção da imagem socioambiental das empresas}

\section{Introdução}

Atualmente, para uma empresa ser grande, é impossível isso acontecer, sem que tal empresa, não leve em consideração o uso sustentável e uma gestão eficiente, Eletrobrás, PROCEL e FUPAI, (2006). No mundo atual, a energia elétrica é imprescindível para a vida moderna, já que ela é considerada um insumo essencial em praticamente qualquer atividade, Mariani e Da Silva (2017).

Esse uso mais intenso da energia começou após a Revolução Industrial, utilizando principalmente o carvão como fonte para a produção e operação das empresas. Por muitos anos, o carvão mineral e o petróleo foram as principais fontes de energia que impulsionaram o desenvolvimento socioeconômico mundial. Porém, com a Crise do Petróleo na década de 1970 e a crescente preocupação ambiental no século XXI, governos, empresas e sociedade em geral se viram obrigados a buscarem fontes alternativas de energia, tais como fontes renováveis e menos poluentes, como por exemplo a energia hidrelétrica, eólica e solar, combustíveis como o etanol e o hidrogênio, dentre outros, bem como uma melhor gestão para uma melhor eficiência na utilização desses recursos, Mariani e Da Silva (2017).

Atualmente, eficiência energética, sustentabilidade, consumo de energia nunca se fez tão necessário, já que estamos passando por um período em que os índices pluviométricos estão abaixo da média. Assim, como nossa matriz energética tem sua fatia principal composta por usinas hidrelétricas, a ANA (Agência Nacional de Águas) e a SIN (Sistema Interligado Nacional) respectivamente, estão emitindo alerta para que a população economize energia.

Os setores industriais do mundo têm um alto consumo de energia, isso se deve à grande expansão do setor de transformação, principalmente pelas indústrias químicas, siderúrgicas, 


\section{0 uso da ISO 50001/14001 de gestão de energia na construção da imagem socioambiental das empresas}

petroquímica, mineradoras e a produção de máquinas e equipamentos, BEN (2021). Este consumo de energia terá um aumento de 40\% até 2040, tal como prevista pela International Energy Agency, IEA (2021). Entretanto, a maior parte da energia produzida e consumida não provem de fontes renováveis causando um grande impacto ambiental. Segundo EPE (2020) o consumo mundial de energia foi de 2,4 TWh em 2020. A China está em primeiro lugar representando 26,6\%, e o Brasil está em sétimo lugar com 2,3\% de todo o consumo mundial de energia. Ainda segundo BEN (2021) o consumo total de energia no Brasil em 2020 o setor industrial liderou o ranking com 32,1\%.

Segundo o Anuário Estatístico de Energia elétrica 2020 EPE (2020) a geração de energia mundial em 2017 foi de $65 \%$ de combustíveis fosseis uma fonte não renovável, diferente da baixa produção de energia por fontes renováveis como 0,1\% Maremotriz e 1,8 Solar isso gera uma preocupação mundial com a sustentabilidade das próximas gerações. Como pode ser observado no Gráfico 1.

Com isso, muitas empresas vêm adotando medidas de forma a construir uma imagem socioambiental, melhorando a imagem e consequentemente sua rentabilidade. Para isso, uma das estratégias é a implantação da normalização de produtos e serviços por meio de normas estabelecidas com intuito de melhoria na qualidade, gestão ambiental, gestão de energia, dentre outros, que são as chamadas certificações ISO - International Organization for Standardization. A ISO 50001 - Sistema de Gestão de Energia, e tem como objetivo estabelecer requisitos que garantam a melhoria contínua do desempenho energético da organização que a implantar, bem como a ISO 14001, que tem como seus principais objetivos, fazer com que empresas e organizações de qualquer tipo, requeiram ferramentas práticas para gerenciar suas responsabilidades ambientais. Mais detalhes podem ser pesquisados na chamada família ISO 14000. 


\section{0 uso da ISO 50001/14001 de gestão de energia na construção da imagem socioambiental das empresas}

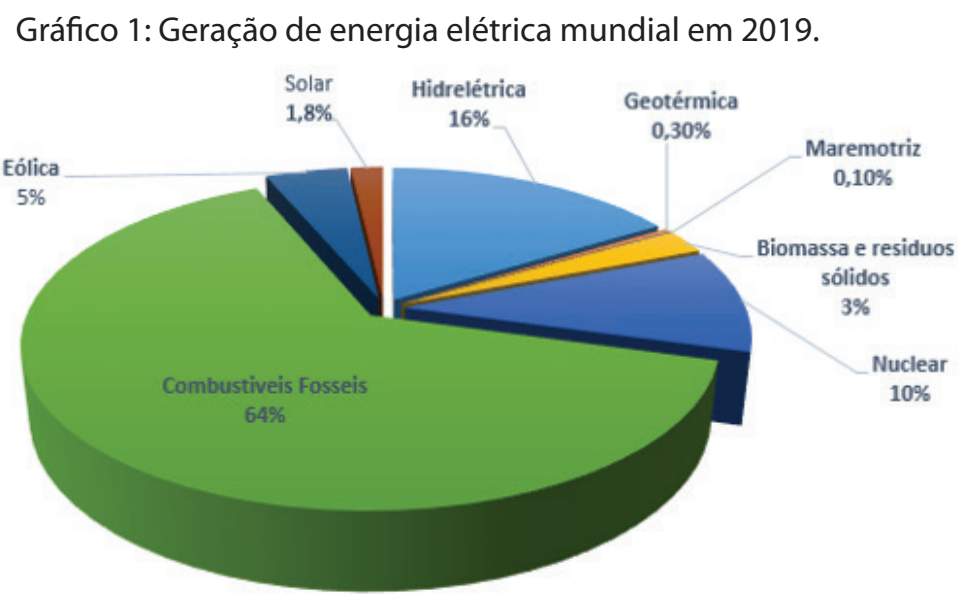

Fonte: Adaptado EPE (2020).

Segundo Schudeleit et. al. (2016)great research effort has been spent on the energy efficiency assessment for energy using products. The ISO (International Organization for Standardization a melhoria da eficiência energética poupa recursos naturais e diminui os custos de produção, possibilitando a produção de bens mais baratos e competitivos, aumentando o desempenho econômico das empresas.

Ainda, segundo a Agência Internacional de Energia IEA, a eficiência energética é a única fonte de energia que todo país do mundo tem em abundância, pois uma forte política de eficiência energética leva a resultados políticos que reduzem os gastos do estado em prol da redução da poluição e da proteção ambiental IEA (2021). 


\section{0 uso da ISO 50001/14001 de gestão de energia na construção da imagem socioambiental das empresas}

Além disso, segundo Sihag Sangwan (2020) o desenvolvimento sustentável, a segurança energética, o aumento do custo da energia e as compulsões políticas forçam as nações e a indústria a se empenharem pela eficiência energética.

Segundo Instituto Brasileiro do Cobre (2021), o emprego dos preceitos da gestão de energia promove o desenvolvimento da cultura de consciência e cuidado em relação ao uso da energia. Dessa forma, como a ISO 50001 pode ser utilizada na gestão de energia para construção de uma imagem socioambiental? Destaca-se a crescente preocupação com uma melhor gestão da energia, tanto empresas e instituições. Também é relevante para a imagem delas perante a sociedade, tanto na questão social como na questão ambiental.

O Objetivo geral é abordar a ISO 50001, bem como observar as boas práticas da ISO 14001, seus aspectos e pontos positivos na construção de uma imagem socioambiental de uma empresa. O objetivo específico é determinar se pode ser considerado um fator relevante para o consumidor e para indústria.

\section{Fundamentação Teórica}

Observando as figuras 1 e 2, percebe-se por que o mundo de uma forma geral vem se preocupando com as questões de gestão de energia, sustentabilidade, eficiência energética e tudo que permeia o entorno desses assuntos, de forma a que se tenha uma racionalização dos recursos e principalmente dos custos. Uma empresa que almeja alcançar uma estrutura de custos racionalizada e tornar-se competitiva no cenário nacional ou mundial, não pode aceitar o desperdício ou utilizar a energia de forma irresponsável e ineficiente. É necessário que haja incentivo para todos os colaboradores a obter o produto ou serviço com a melhor qualidade possível e o menor consumo de energia, Eletrobrás (2005). 


\section{0 uso da ISO 50001/14001 de gestão de energia na construção da imagem socioambiental das empresas}

Figura 1. Matriz Energética Global.

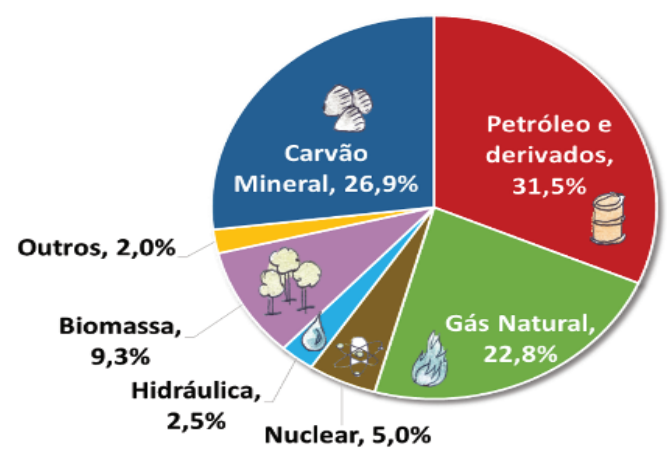

Fonte: (IEA, 2020).
Figura 2. Matriz Energética Brasileira.

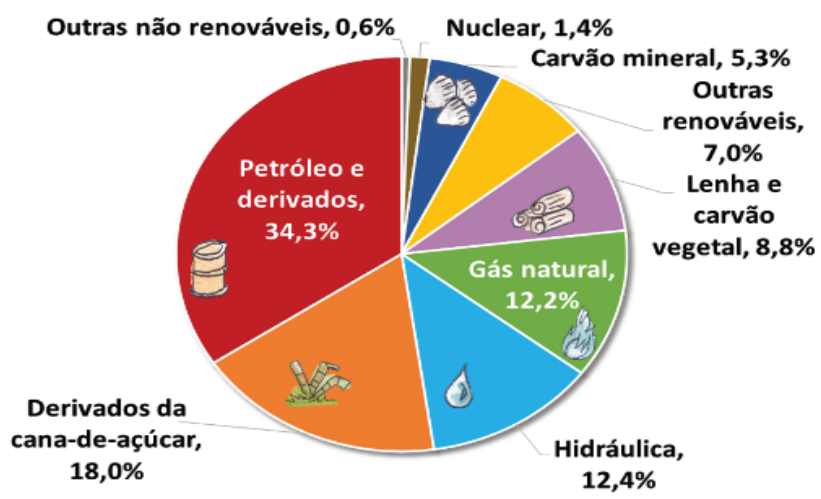

Fonte: (IEA, 2020).

Em Christen (2019) encontra-se os conceitos físicos básicos de potência e eficiência, na geração, conservação e armazenamento de energia. Em WAY2 (2021) encontra-se as definições e os conceitos da gestão de energia como uma forma inteligente de reduzir e controlar os custos com energia em uma empresa, resultando em eficiência energética e aumentando a competitividade do negócio e sua sustentabilidade no mercado, entrando em conformidade com a ISO 50001 e a ISO 14001.

\section{A importância da gestão de energia}

Em vista do que se observa nas figuras 3 e 4, vê-se a crescente demanda por energia e suas respectivas dificuldades em produção, os atuais desafios ambientais ligados às mudanças climáticas, 


\section{0 uso da ISO 50001/14001 de gestão de energia na construção da imagem socioambiental das empresas}

criou a necessidade de se considerar estratégias de gestão eficiente de geração de energia, de consumo, e principalmente no combate dos desperdícios da energia Kiperstok (2017) e Paixão (2020). Ressalta-se que os avanços tecnológicos bem como as alterações nas diversas maneiras de se utilizar a energia estimulam as empresas a terem uma política de gestão de energia Christen (2019) e Eletrobrás, PROCEL e FUPAI, (2006). Os autores Matsunaga et al. (2021), trouxeram uma revisão bibliográfica de como a manufatura inteligente e os sistemas ciberfisicos, no contexto da indústria 4.0 estão alavancando os resultados na eficiência energética. ADICIONEI.

Figura 3. Evolução das fontes geradoras de energia até 2050.

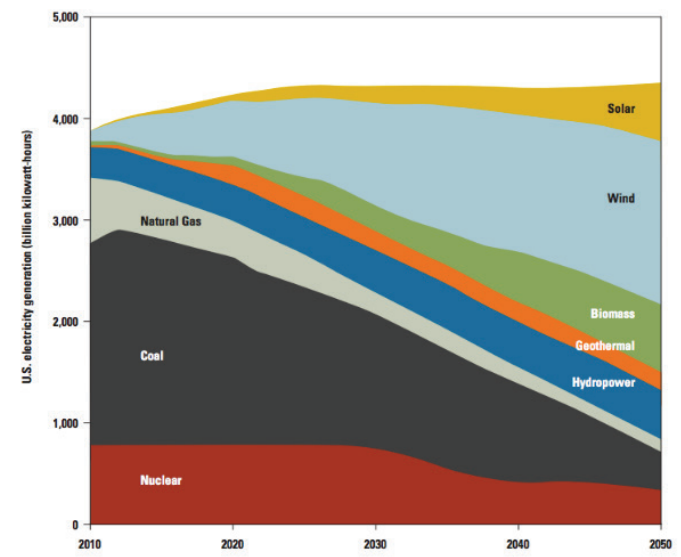

Fonte: UCE, (2013).
Figura 4. Cinco Previsões para a energia em 2030.

Consumo Mundial de Energia até 2060

(Cenário: Crescimento Sustentado)

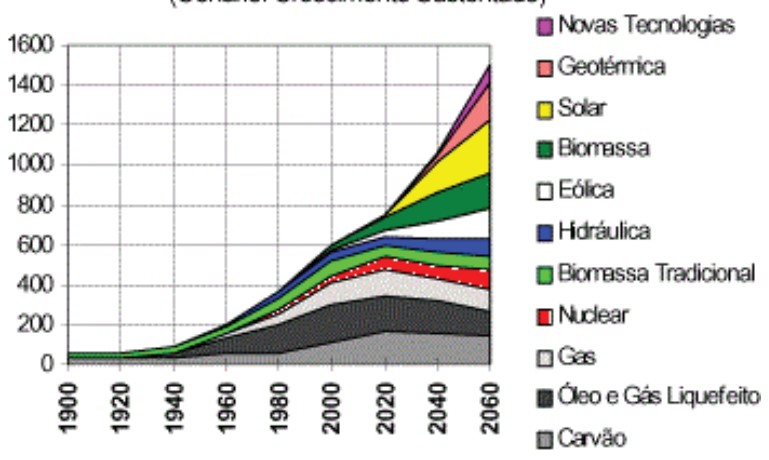

Fonte: WEF, (2016). 


\section{0 uso da ISO 50001/14001 de gestão de energia na construção da imagem socioambiental das empresas}

Vale destacar que há uma busca por uma melhor eficiência nos meios de potência, geração, armazenamento e distribuição, dos meios, de energia Christen (2019) e Santos (2013). Observa-se também que, a melhoria da eficiência energética de uma organização exige uma gestão energética metódica, ligada também à mudança de hábitos dos envolvidos Huang (2011). Como forma de implementar uma política de eficiência energética efetiva e gere resultados duradouros e significativos, a gestão de energia é uma opção viável, já que ela é capaz de identificar como e onde a energia é utilizada, se há desperdícios e como corrigi-los, implementando medidas de melhoria contínua Paixão (2020).

Figura 5: Oferta interna de energia.

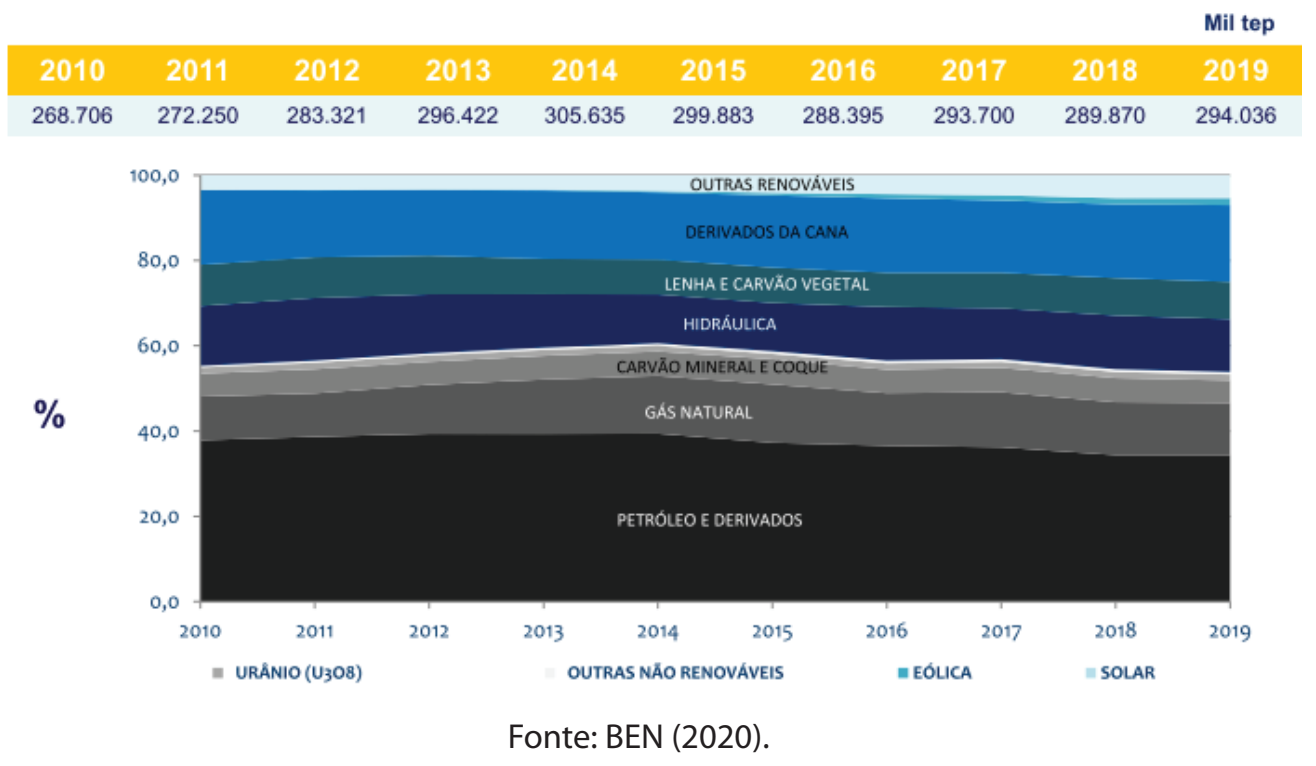

Revista Tuiuti: Ciência e Cultura, v.7 n.63. p. 52-73, Curitiba, 2021 


\section{0 uso da ISO 50001/14001 de gestão de energia na construção da imagem socioambiental das empresas}

Figura 6: Comparação do consumo de energia. Mundo versus Brasil e fontes Não Renovável versus Renováveis.

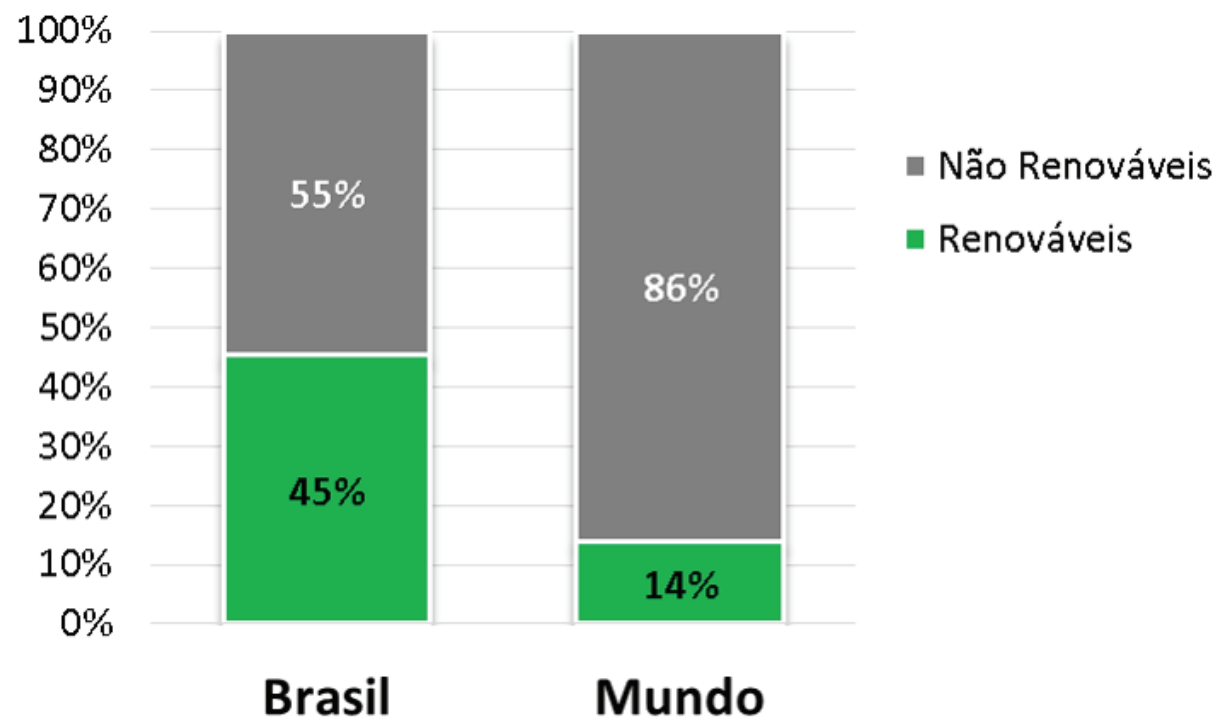

Fonte: EPE (2021).

Medidas isoladas de eficiência energética normalmente não duram muito tempo, já que não há um acompanhamento. Sendo assim, os benefícios da gestão de energia além de promover uma maior eficiente energética duradouras e efetivas por meio de um acompanhamento sistemático, contribui para a redução de gases causadores do efeito estufa, aumento da produtividade e economia Instituto Brasileiro do Cobre (2019). 


\section{0 uso da ISO 50001/14001 de gestão de energia na construção da imagem socioambiental das empresas}

Todo tipo de atividade econômica deve repensar o custo da energia em suas operações. Para WAY2:

A energia é considerada um insumo operacional extremamente relevante, e conseguir gerenciá-los de maneira inteligente pode gerar uma economia significativa para o negócio e aprimorar de maneira expressiva a sua competitividade, (WAY2, 2021).

\section{Importância da gestão de energia e eficiência no gerenciamento dos recursos}

Sabe-se que a gestão de energia é uma forma de racionalização dos custos. Uma empresa que almeja alcançar uma estrutura de custos racionalizada e tornar-se mais competitiva não pode aceitar o desperdício ou utilizar a energia de forma irresponsável e ineficiente. É necessário que haja incentivo de todos os colaboradores a obter o produto ou serviço com a melhor qualidade possível e o menor consumo de energia Eletrobras (2005), levando em conta as boas práticas apontadas nas ISO 50001 e 14001.

A WAY2 (2021) define a gestão de energia como uma forma inteligente de reduzir e controlar os custos com energia em uma empresa, resultando em eficiência energética e aumentando a competitividade do negócio e sua sustentabilidade no mercado.

A crescente demanda por energia e os atuais desafios ambientais ligados às mudanças climáticas, criou a necessidade de se considerar estratégias de gestão eficiente de geração de energia, de consumo, e principalmente no combate dos desperdícios da energia Kiperstok (2017) e Paixão 


\section{0 uso da ISO 50001/14001 de gestão de energia na construção da imagem socioambiental das empresas}

(2020). Ressalta-se que os avanços tecnológicos e alterações nas diversas maneiras de se utilizar a energia estimulam as empresas a terem uma política de gestão de energia Iusnatura (2021).

Vale destacar que a melhoria da eficiência energética de uma organização exige uma gestão energética metódica, ligada também à mudança de hábitos dos envolvidos (HUANG, 2011). Como forma de implementar uma política de eficiência energética efetiva que gere resultados duradouros e significativos, a gestão de energia é uma opção viável, já que ela é capaz de identificar como e onde a energia é utilizada, se há desperdícios e como corrigi-los, implementando medidas de melhoria contínua Paixão (2020). Dessa forma a empresa garante um bom relacionamento com a sociedade, fica em legalidade internacionalmente, caso tenha interesse em comercializar com o mundo e principalmente, garante um melhor gerenciamento dos seus recursos, seja naturais ou financeiros. Mantendo essas boas boas práticas em conformidade com as ISO 50001 e ISO 14001 por vários anos consequitivos, a empresa pode até se candidatar para certificação ISO.

\section{Responsabilidade socioambiental: ISO's 50001 e família 14000}

De acordo com Hart \& Milsten (2003), uma empresa sustentável utiliza-se de estratégias empresariais e práticas que agregam valor ao promoverem um mundo mais sustentável, seja no âmbito econômico, ambiental ou social.

Muitas empresas tratam a questão da sustentabilidade como uma oportunidade de negócio, abrindo oportunidades para a redução de custos e riscos, e em muitos casos aumentando seus rendimentos e sua participação de mercado através da inovação, ligados à sustentabilidade e à responsabilidade social corporativa que se refletem na imagem da empresa Azevedo et al. (2015). 


\section{0 uso da ISO 50001/14001 de gestão de energia na construção da imagem socioambiental das empresas}

Azevedo et al. (2015) discorrem ainda que as ações de responsabilidade social e ambiental de uma organização estão vinculadas a sua reputação, o que afeta a sua competitividade, de modo que as empresas estão legalmente sendo obrigadas a cumprir requisitos de leis impostas e destaca-se ainda que a sociedade está cada vez mais sendo exigente em relação ao consumo de bens e serviços de organizações que possuem, atitudes voltadas à questão social e ambiental, de maneira a garantir um futuro para as próximas gerações.

As empresas que buscam responsabilidades socioambientais, em conformidades com as ISO's 50001 e a família 14000, podem começar seguindo as sugestões descritas em um artigo que se encontra no site da empresa VGR, que é uma empresa do setor de gestão de resíduos.

A VGR destaca que:

As práticas sustentáveis podem melhorar a imagem da sua empresa, pois buscam diminuir os impactos ambientais das suas atividades, reduzir os custos de produção e do produto final [...]. Adotar práticas sustentáveis não é só uma decisão de proteger o meio ambiente. É uma estratégia dos empreendedores que viram que a cada dia aumenta o número de consumidores conscientes que optam por produtos que garantem a sustentabilidade." (VGR, 2021).

Há diversas justificativas que levam as empresas/organizações a buscarem por responsabilidades socioambiental, bem como se alinharem com as respectivas normas internacionais 50001/14000 que regulamentam/premiam tais organizações nesse sentido. Contudo há quatro justificativas predominantes. A primeira é a obrigação moral, que está relacionada a forma de agir de maneira correta, segundo as normas vigentes, onde os componentes da organização devem honrar os valores éticos, legais, respeitar as pessoas, as comunidades e o meio ambiente, ISSO 50001 e família 


\section{0 uso da ISO 50001/14001 de gestão de energia na construção da imagem socioambiental das empresas}

ISO 14000. A segunda é a sustentabilidade, cujo intuito é a vigilância do meio ambiente e da comunidade, segundo os parâmetros pré-estabelecidos na sociedade atual Kruglianskas (2013) e Almeida (2007). A terceira é a licença de operação, que está relacionada às regulamentações governamentais, ISO 50001 e família ISO 14000, e as NR's correspondentes, no caso do Brasil, e por último, tem-se a reputação, que está atrelada à imagem perante o público, marca, elevação de moral e valorização Porter e Kramer (2009).

\section{ISO 50001 e família ISO 14000}

Atualmente diversas organizações estão optando pela certificação ISO 50001 e a família ISSO 14001, de forma a assegurar uma gestão de energia mais eficiente e sistematizada, Kruglianskas (2013) e Almeida (2007), facilitando o processo de gestão. As referentes ISO's, apresentam as diretrizes e requisitos que devem ser implementados para que uma organização obtenha a certificação. Ao cumprir esses requisitos, as empresas, consequentemente, realizam a gestão de energia (WAY2, 2021).

Atualmente, os assuntos relacionados a sustentabilidade estão em alta Kruglianskas (2013) e Almeida (2007). E quando uma empresa possui ações voltadas para o meio ambiente, é visto como algo positivo diante do mercado e da sociedade. Cabe ressaltar que a ISO 50001 e a ISSO 14001 não são obrigatórias, assim como as outras normas de sistema de gestão ISO (VERDE GHAIA, 2021).

A procura pela certificação ISO 50001 pelas organizações são influenciadas tanto por fatores internos quanto fatores externos. Crises nacionais e internacionais que geram transformações 


\section{0 uso da ISO 50001/14001 de gestão de energia na construção da imagem socioambiental das empresas}

repentinas das condições macroeconômicas (de negócios) é um exemplo relevante, já que atrai a atenção e precaução para si Abesco (2021).

Figura 6. Características da ISO 50001. Benefícios da implementação da ISO 5001.

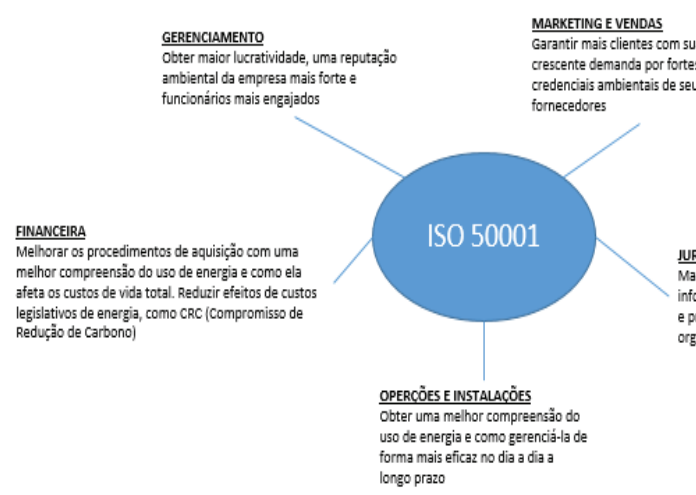

Fonte: BSI (2021).
Figura 7. Características da família ISO 14001.

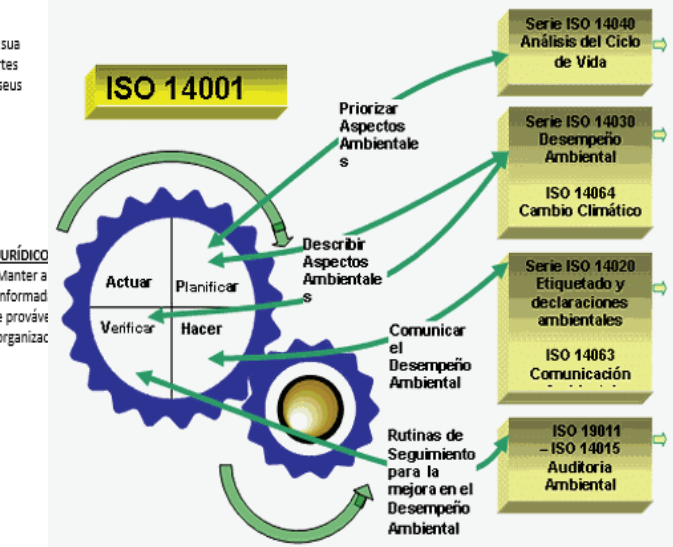

Descripción del desempeno ambiental de Procesos y Descripción del desempeño ambiental de Organizaciones

Infornación relacionada con $\varepsilon$ desempeño Prndurtos

Infornación relacionada con los medios para mejora el desempeño ambiental de Organizaciones

Fonte. PALOMINO, (2005).

A implementação da ISO 50001 e da família ISO 14000, resultam na redução das emissões de gases causadores do "efeito estufa local" e de diversos outros impactos ao meio ambiente ligados à energia e os custos/economia de energia. A ISO 50001 e a família ISSO 14000 pode ser aplicada a qualquer tipo de negócio, sempre que possível, de todos os tamanhos, não importando as condições geográficas, sociais e culturais da referida empresa/organização. Para que as implantações das normas sejam bem-sucedidas, é necessário que haja o comprometimento de todos os níveis e funções da organização Wysokiå ka e Senkus (2019), Kruglianskas (2013) e Almeida, (2007). 


\title{
0 uso da ISO 50001/14001 de gestão de energia na construção da imagem socioambiental das empresas
}

\section{Metodologia}

Neste trabalho foi adotada a metodologia de pesquisa bibliográfica de forma que busca um direcionamento para as questões levantadas tanto no resumo quanto na introdução. Segundo a Universidade do Estadual de Goiás - UEG, entende-se que a pesquisa bibliográfica:

\begin{abstract}
Acrescenta-se ainda nessa lista de referências a serem consultadas, trabalhos de conclusão de curso, dissertações, dentre outras fontes, tais como sites de empresas e departamentos de universidades, que estejam engajados nesses processos de busca por melhorias contínua UEG (2021).
\end{abstract}

A revisão da literatura ajuda a identificar e avaliar o conhecimento existente para reconhecer as futuras áreas de pesquisa e para fomentar o interesse em tópicos específicos (SIHAG e SANGWAN, 2020).

O intuito é realizar um levantamento bibliográfico relacionado a ISO 50001 e a família de ISO 14001, são as suas características e pontos positivos relacionados a responsabilidades sociais e ambientais, bem como a implementação de suas recomendações, visando um bem comum de todos no sentido socioambiental. Sendo assim, a primeira etapa é a pesquisa bibliográfica sobre o tema, cujas fontes são livros, artigos acadêmicos, dissertações, trabalhos de conclusão de cursos, guias técnicos e sites de organizações relacionadas ao assunto abordado, dentre outras fontes que delimita o assunto abordado aqui. Dessa forma tem-se uma maior confiabilidade das informações. Em uma segunda fase desse trabalho, em um futuro não muito distante, fará se á, a etapa e análise das informações e dados coletados sobre a ISO 50001 e a família da ISSO 14001, para um melhor 


\section{0 uso da ISO 50001/14001 de gestão de energia na construção da imagem socioambiental das empresas}

entendimento sobre, a gestão de energia, o consumo inteligente/responsável da energia, a geração sustentável, via fontes de energias renováveis, a fim de identificar se a ISSO 50001 e a família 14001, na gestão de energia pode levar a construção de uma imagem socioambiental de uma empresa.

A segunda etapa é a análise das informações e dados coletados sobre a ISO 50001 e da ISO 14001, de modo a buscar, uma prática, uma melhor gestão de energia, a fim de identificar sua influência na gestão de energia industrial e socioambiental, para uma melhoria constante da sociedade, de modo a buscar uma sociedade melhor. Isso pode levar a construção de uma imagem socioambiental de uma empresa, perante a sociedade.

\section{Conclusão}

Em tese de tudo que foi levantado, levando em conta, sustentabilidade, eficiência energética, consumo de energia, processo de gestão de energia. Buscou-se fazer um questionamento das boas práticas de gestão e geração de energia de forma sustentável, buscando o bem-estar comum da sociedade, buscando uma estratégia, no desenvolvimento de novos mecanismos de produção, de modo a buscar uma maior eficiência energética e uma melhor gestão dos recurso naturais, levando em consideração as ISO 50001 e a família ISO 1400. Esse tema vem sendo estudado há algumas décadas e vem ganhando força nos últimos anos, por ser de interesse global, de modo a reduzir o consumo de energia e aumentar a oferta de novas formas de geração, de modo a reduzir os impactos ambientais. 


\section{0 uso da IS0 50001/14001 de gestão de energia na construção da imagem socioambiental das empresas}

\section{Referência}

ALMEIDA, F., Os Desafios da Sustentabilidade: Uma Ruptura Urgente. Elsevier, 2007.

ABESCO. ISO 50001 - Gestão de Energia. Disponível em:< http://www.abesco.com.br/pt/ iso-50001-gestao-de-energia/ > . Acesso em: 22 Junho 2021.

AZEVEDO, J. B.; ENDE, M. V.; WITTMANN, M. L. Responsabilidade Social E A Imagem Corporativa: O Caso De Uma Empresa De Marca Global. Revista Estratégia \& Negócios. Santa Maria, 2015.

BSI. Save money through better energy management with ISO 50001. 2021.

BEN. Balanço Energético Nacional, 2021.

CHRISTEN, T. Efficiency and Power in Energy Conversion and Storage: Basic Physical Concepts. By Taylor \& Francis Group, LLC. 2019

Dos SANTOS, M. A. Fontes de Energia Nova e Renovável. LTC, 2013.

ELETROBRÁS, PROCEL e FUPAI. Conservação de Energia: Eficiência Energética de

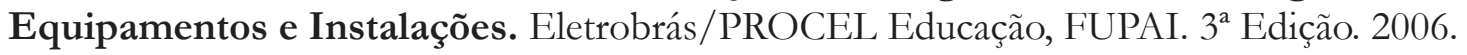

EPE, https://www.epe.gov.br/pt/abcdenergia/matriz-energetica-e-eletrica, Ano base 2021.

EPE. Anuário Estatístico de Energia Elétrica 2020 - Ano base 2019. Empresa de Pesquisa Energética, p. 256, 2020.

HART, S. L.; MILSTEN, M. B. Creating sustainable value. Academy of Management Executive. v. 17, n. 2, pp. 56-67, 2003.

HUANG, E. G. T. Entendendo Os Requisitos Da Certificação De Sistemas De Gestão Da Energia. Energia e Sustentabilidade. SGS, 2011. 


\section{0 uso da IS0 50001/14001 de gestão de energia na construção da imagem socioambiental das empresas}

IEA. Key World Energy Statistics. 2021.

INSTITUTO BRASILEIRO DO COBRE. Guia Para Aplicação Da Norma ABNT NBR ISO 50001: Gestão De Energia. 84 p. Cooper Alliance: São Paulo, 2019.

INTERNATIONAL ORGANIZATION FOR STANDARDIZATION. ISO 50001:2018 Energy management systems - Requirements with guidance for use. International Organization for Standardization. 2018.

IUSNATURA. Tudo Sobre a ISO 50001. Sistema de Gestão de Energia. Disponível em: <https://iusnatura.com.br/iso-50001/>. 22 junho 2021.

Mariani, L.; da Silva, N. N. dos R. Eficiência energética e qualidade de energia. Editora e Distribuidora Educacional S.A. 2017.

KIPERSTOK, A; KIPERSTOK, A. C. Technology Improvements or Influencing User Behaviour for Water Savings in Administrative and University Buildings: Which One Should Come First? Frontiers in Civil Engineering. Salvador, 2017.

KRUGLIANSKAS, I., Gestão Estratégica da Sustentabilidade. CAMPUS - GRUPO ELSEVIER 2013.

MATSUNAGA, F.; VALLE, P. D.; DESCHAMPS, F. Optimization of energy efficiency in smart manufacturing through the application of cyber-physical systems and industry 4.0 technologies - A systematic review. 2021.

SCHUDELEIT, T.; Züst, S.; Weiss, L.; Wegener, K. The Total Energy Efficiency Index for machine tools. Energy. v. 102, p. 682-693, 2016.

SIHAG, N.; SANGWAN, K. S. A systematic literature review on machine tool energy consumption. Journal of Cleaner Production. v. 275, p. 123125, 1 Dez. 2020.

WYSOKIA,,KA-SENKUS, A. Effective energy management in the organization in the context of implementing the sustainability concept. Proceedings of the 33rd International Business Information. 


\section{0 uso da IS0 50001/14001 de gestão de energia na construção da imagem socioambiental das empresas}

MANAGEMENT ASSOCIATION CONFERENCE, IBIMA 2019: Education Excellence and Innovation Management through Vision. 2020. Anais. 2019.

PAIXÃO, M. F. B. Sistema De Gestão De Energia Em Universidades Federais Brasileiras: Um Estudo De Caso Na Escola Politécnica Da Universidade Federal Da Bahia. 230 f. Dissertação (Mestrado em Engenharia Industrial) - Universidade Federal da Bahia. Salvador, 2020.

PALOMINO, J. A. D., Sistemas Integrados de Gestión - ISO 9000? ISO 14000? OHSAS 18000. 2005. <https://www.monografias.com/trabajos38/sistemas-integrados-gestion/ sistemas-integrados-gestion2.shtml>

PORTER, M.E.; KRAMER, M.R. Estratégia E Sociedade: O Vínculo Entre Vantagem Competitiva E Responsabilidade Social Das Empresas. Rio de Janeiro: Elsevier, 483-507, 2009.

UEG - UNIVERSIDADE ESTADUAL DE GOIÁS. O que é Pesquisa Bibliográfica. Disponível em: < http://www.ueg.br/noticia/36347_o_que_e_pesquisa_bibliografica>. Acesso em: 22 jun 2021.

UCE: Fontes Renováveis: Energia com que se pode contar Intensificação das energias renováveis. União de Cientistas Engajados. Abril de 2013. (https:/ / br.usembassy.gov/pt/ fontes-renovaveis-energia-com-que-se-pode-contar/).

VERDE GHAIA. Qual A Importância Da Certificação ISO 50001 Em Gestão De Energia Para A Sua Empresa. Disponível em: < https://www.verdeghaia.com.br/gestao-deenergia/>. Acesso em: 22 Junho 2021.

VGR. Sete Práticas Sustentáveis Que Podem Melhorar A Imagem Da Sua Empresa.

Disponível em: < https://www.vgresiduos.com.br/blog/sete-praticas-sustentaveis-quepodem-melhorar-a-imagem-da-sua-empresa/>. Acesso em: 22 Junho 2021. 


\section{0 uso da ISO 50001/14001 de gestão de energia na construção da imagem socioambiental das empresas}

WAY2. Gestão De Energia: O Que É E Como Fazer. Disponível em: < https://www.way2. com.br/blog/gestao-de-energia/>. Acesso em: 10 Maio 2021.

WEF. Cinco Previsões para a energia em 2030. World Economic Fórum, 2016. 